\title{
Middle Cranial Fossa Meningioma
}

National Cancer Institute

\section{Source}

National Cancer Institute. Middle Cranial Fossa Meningioma. NCI Thesaurus. Code C5586.

A mening ioma that affects the middle cranial fossa. 